\title{
Characterizing the school-to-work transitions of young men and women in Tunisia
}

\section{Farouk Kriaa, Mohamed Bouhari}

\author{
University of Tunis Al Manar \\ Campus Universitaire Farhat Hached B.P. $n^{\circ} 94$ - ROMMANA 1068 Tunis, Tunisia \\ Faculty of Economics and Management of Tunis
}

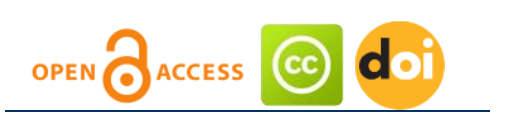

Article history:

Received: May 16, 2018

1st Revision: August 25,

2018

Accepted: October 25,

2018

\section{JEL classification:}

E24

$\mathrm{J} 64$

$\mathrm{J} 01$

\section{DOI:}

10.14254/jems.2018.3-2.7

\begin{abstract}
This paper investigates the characteristics and determinants of the transition of young men and women from education (dropping out) to work in Tunisia, using data from the Panel Study of Tunisia Labor Market 2014 (TLMPS 2014). One of the main findings is that 17 per cent of the 15 to 35 years old population remains in transition. One - third had completed the transition. The remaining (55 per cent) had not started transition. The transited category is strongly male-dominated while young females face a particularly difficult time. Youths who were still in transition were largely unemployed. Econometric method (Kaplan-Meier or product limit estimator) is used to analyze the determinants of unemployment duration. Results point to differences between men and women in the difficulty of getting a decent job. They confirm that individual characteristics (gender, area of residence and level of education...) influence the length of transition from school to the labor market. Indeed, we found the following. First, for most youth, the school-to-work transition is not long to a first job, but it takes on average more five years to complete the transition to a stable or satisfactory job. One third of young males and females found a first job through contact with employers. Second, transition period decreases substantially as education level increases. Third, the rural - urban gap continues to be significant. Fourth, the probability of longer unemployment is found to be considerably higher among women and lower education. The study offers some recommendations in terms of economic policy on the insertion of young people.
\end{abstract}

Keywords: school-to-work transition, unemployment duration, Kaplan - Meier method 


\section{Introduction}

Transition from school to work is a crucial and complicated stage in the life of a young person at any level of education. It is designed to measure the ease or difficulty with which young people are able to access decent work.

The labor market literature contains numerous studies examining the transition of young people from school to work and its determinants. The school-to-work transition survey was developed to identify three major segments of the youth population. Methodologies include the young person who had 'not yet started' the transition, the young person who was 'in transition' and the one who had 'transited' to decent work.

Studies have been carried out during the past few years, in Syria in 2012, (Rosso, Bardak, \& Zelloth), in Jordan in 2014, (Valentina \& Nader), in Jamaica in 2014 (Statistical Institute of Jamaica; The Planning Institute of Jamaica), and in Egypt in 2014 (Ghada, Mohamed \& Mona). Generally theses studies have shown that youth experience increasing difficulties in completing the transition to economic independence and adulthood. Young people are more vulnerable to unemployment and the transition from school to work is proven to be an extremely lengthy. The formal schooling system does not provide them with the skills needed for the labor market.

The issue is believed to be particularly important in Tunisia where the labor market is unable to absorb all available workers. Despite the great efforts of governments to enhance the level of education of the population, the major interventions on the demand side and the efforts to reform the education and the vocational school system, youth unemployment is close to or above 25 per cent. The improvements in the level of education of the population have not translated into employment growth. Additionally, massive demographic changes leading to a rising proportion of youths in the labor market together with increasing urbanization have deteriorated the labor market prospects of recent cohorts of workers.

This situation raises the question of how young individuals cope without jobs. An analysis of the reasons why the labor market is unable to absorb all available workers goes beyond the scope of this study. The main objective is to investigate the determinants of the transition of young men and women from school to work in Tunisia. This study contributes to the literature by examining the relationship between unemployment duration and the personal and household characteristics and the local labor market conditions using data from the panel survey of Tunisia Labor Market (TLMPS 2014) to construct a cross-section of durations of unemployment spells.

To our knowledge, this is the first study on the duration aspect of unemployment in Tunisia although the incidence of unemployment was considered by earlier studies (Boughzala, 2004; Marco \& Audrey, 2011; Haouas, Sayre, \& Yagoubi, 2012). Our analysis focuses on youth (in an extended sense) aged between 15 and 35 years as the unemployment rate drops sharply after the age of 35 years. We will attempt to examine several aspects of transition and insertion of youth and explore the factors that influence their transition. We distinguish mainly between youth who have transited and those who remain in transition.

This paper is organized as follows. Section 2 focuses on the concept of transition. Section 3 details the characteristics of youth who have transited. Section 4 describes youths' transition process. In Section 5, we focused on studying the factors influencing the duration of unemployment, using Kaplan Meier method. Conclusions appear in section 6.

\section{The Stages of transition}

This section provides background information about the stages of transition in order to identify the possible determinants of young men's and women's school-to-work transitions in Tunisia.

\subsection{Basic concepts and definitions}

Young people's transition to the labor market denotes not only the time span between their graduation and their first job, but also relates to qualitative factors, such as whether the job is stable and or satisfactory.

Labor market transition defines the passage of a young person from school (or entry to the first economic activity) to the first stable or satisfactory job. Stable employment is defined in terms of the employment contract (written or oral) and the contract duration (greater than 12 months). The stages of transition are not intended to be a normative framework. Two comments should be made in this respect. First, inclusion a contract excludes the self-employed from employment 
status, as the employment relationship is not defined by a contract. The opposite of stable employment is temporary employment, or wage and salaried employment of limited duration.

Second, satisfactory employment is a subjective concept, based on the self-assessment of the jobholder. Having a job and being able to earn a living creates a feeling of participation, security and dignity. This involved a degree of subjective judgment which is open to criticism. The opposite is termed non-satisfactory employment, implying a sense of dissatisfaction with the job. The inclusion of youth in satisfactory self-employment and satisfactory temporary employment tend to overestimate the category "transited youth".

The concept of transition from school to employment has been the subject of several studies, although its meaning varies slightly from one author to another (Ryan, p. 2003). We retain the definition that considers transition from school to employment as the passage of a person (aged 15 to 35 years) from school to the first stable or satisfactory job (World Bank, 2008). Transition from school to work is the time span between the end of education and the first regular job entry

According to the literature on labor market transition (El Zanaty \& Associates, 2007), we distinguish three transition stages: transited, in transition or transition not yet started (see table A1 in Appendix). In this paper, we focus on those individuals who have transited (section 3) and in transition (section 4).

\subsection{Shares of transited, in transition and transition not yet started}

The data reveal that more than one- quarter of respondents has transited from school to work (Figure 1). The survey estimates that 17.31 per cent were still in transition. The remaining 55.30 per cent had not started the transition.

The survey shows that a higher proportion of males (41.61 per cent) than females (15.05 per cent) have transitioned, while a higher proportion females (70.39 per cent) than males (37.92 per cent) have not started transition.

Figure 1: Youth population by stage of transition (\%)

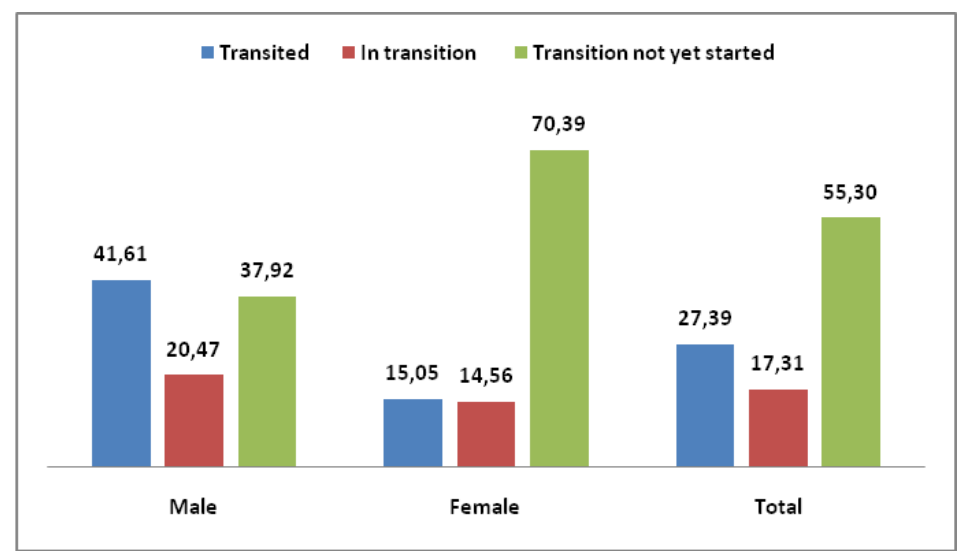

Source: TLMPS 2014 and authors' calculation

The results illustrate a large gender discrepancy in the transition from school to work. The majority of women have not initiated their transition, while the majority of men are transited or in transition. This is due to the fact that young women have more difficulties than men to find a permanent career position.

\section{Transited youth}

For young people who have started their transition, figure 2 shows that the surveyed transited youth were mostly in a stable job (satisfactory or non-satisfactory employment) (75 per cent). Approximately 13 per cent of transited youth, however, indicated that despite the temporary nature of their current employment, they were satisfied with the job. The proportion of respondents who were in satisfactory self-employment is limited to 12 percent. 
Figure 2: Transited youth by current activity

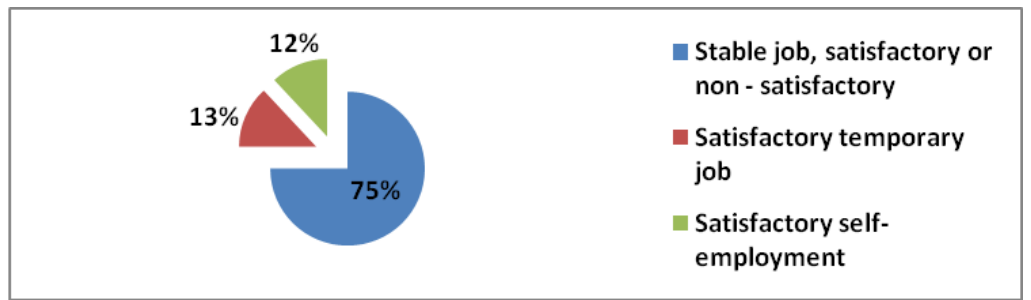

Source: TLMPS 2014 and authors' calculation

\section{Youth in transition}

For young people in transition, we retain the expanded or broad definition of unemployment. This definition includes discouraged job-seekers: "those who were not employed a single hour during the reference week, who want to work and are available to start work within two week but are not actively searching for a job in the past three months".

Figure 3 shows that almost 18 percent of youth in transition are inactive and planning to join the labor force later (non-students with an aim to look for work in the future) while 67 percent are unemployed. The remaining 15 per cent of youth in transition were in the subcategory of nonsatisfactory self-employment or temporary employment.

Figure 3: In-transition youth by current activity

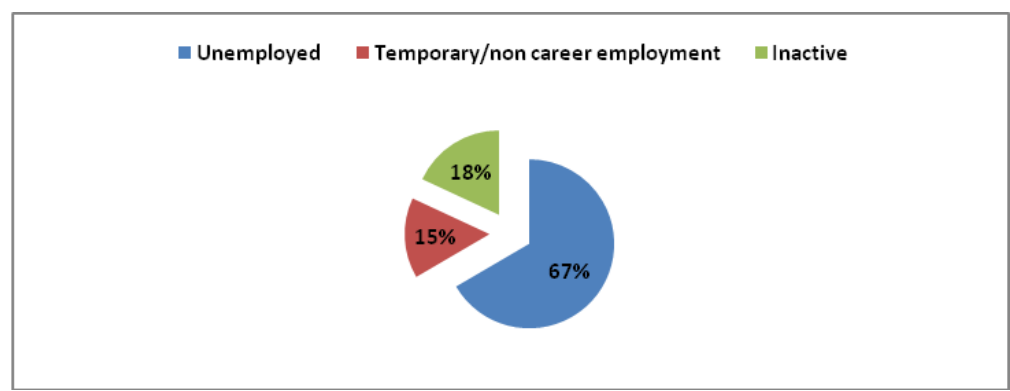

Source: TLMPS 2014 and authors' calculation

\section{Youth who have not started the transition}

As previously indicated, 55.3 per cent of youth had not started the transition. As shown in figure 4, among respondents who were out of the labor force with no intention to look for work, the clear majority were females (58.82 per cent). Among respondents who were still in school, the majority were males (69.96 per cent). Among young males, the share of inactive non-students with no plans to work in the future takes a non-negligible share of 30.04 per cent.

Figure 4: Youth who had not started the transition

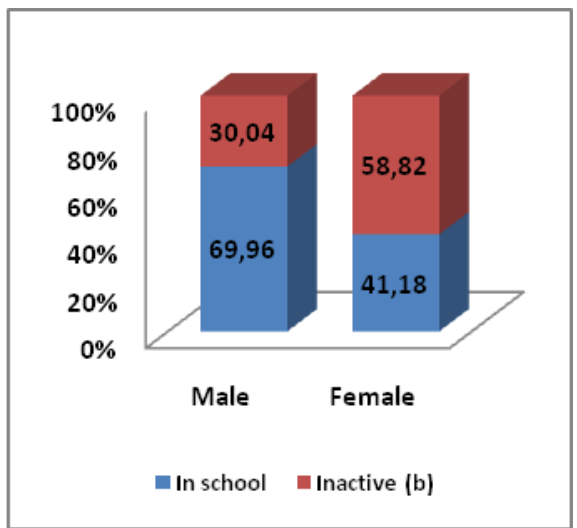

Source: TLMPS 2014 and authors' calculation

Inactive (b): out-of-school and out of the labor force with no intention to look for work 


\section{Youth in transition and transited}

We exclude the youth who have not yet started the transition in order to look only at the economically active categories of transition.

As table 1 shows, two third (61.23 per cent) of youth had completed the transition, with a marked difference between men and women (67.02 per cent and 50.83 per cent, respectively).

49.50 per cent of economically active males had attained stable employment and 9.26 per cent were in satisfactory temporary employment.

\begin{tabular}{llccc}
\hline Table 1: Youth in transition and transited by sub-category and by gender (\%) \\
\hline & Sub- category & Total & Male & Female \\
\hline \multirow{3}{*}{ Transited } & Stable employment & 45.65 & 49.50 & 38.65 \\
& Satisfactory Self employment & 8.48 & 8.26 & 9.87 \\
& Satisfactory temporary employment & 7.15 & 3.31 & 32.18 \\
\multirow{2}{*}{ In transition } & Unemployed (a) & Non satisfactory Self-employment or temporary & 25.33 & 21.57 \\
& employment & 6.51 & 6.03 \\
\hline & Inactive (b) & 6.88 & 5.37 \\
\hline
\end{tabular}

Source: TLMPS 2014 and authors' calculation.

(a) Relaxed definition, (b) Nonstudent with plan to work in future

The obtained results reinforce the findings of recent studies. The difference in percentage of youth who had transited and those who remained in transition becomes even more evident.

In Egypt, Ghada, B., Mohamed, R. and Mona, M. (2014) showed that earlier more male youth had transited, at 51.7 per cent, compared to only 16.3 per cent of female youth. Slightly more female youth are still in transition (30.3 per cent), compared to 28.5 per cent of male youth.

They have found that young men were almost twice as likely as young women to have completed the transition, with the greatest percentage of transited young men having attained a satisfactory temporary job (37.0 per cent of economically active males).

In Jamaica, in 2014, a large proportion of Jamaican youth aged 15-29 were still in transition (41.3 percent). Among youth aged 20-24 years who started transition, 46.2 per cent successfully completed it and 53.8 per cent were still in transition (The Statistical Institute of Jamaica, 2014).

In Jordan, a study showed that 52.2 per cent (a majority) of youth fall into the category of transition not yet started, about 28.8 per cent of youth consist of those who completed their transition to stable and/or satisfactory employment and 19 per cent are still in transition (Valentina \& Nader, 2014).

In sum, the results indicate that transition stages are highly gender sensitive.

The largest share of youth in transition constituted unemployed youth (76 per cent). Three quarters of youth who had transited, had attained stable employment (75 per cent).

Regarding youth in transition and who had transited, young males were more likely to have achieved their current stable and/satisfactory or non- satisfactory employment than females.

Youth who had completed their transition made up more than two third of total youth (transited and in transition), with here again significant differences between men and women.

Women have a higher probability of remaining in transition and men are more likely to have transited. The highest proportion of females was found in the unemployment category. The results mean that the school-to-work problems run wide and deep. Indeed, where unemployed youth is high, employment problems may arise associated particularly with macroeconomic difficulties, labor market programs and schooling patterns.

\section{Characteristics of young people who transited}

In this section, we examine the young people who transited and who represent 27.39 per cent of young people (Figure 1). This amounts to examining the distribution of this category according to youth characteristics (gender and environment) and job characteristics that may lead to complete the transition: permanent, temporary and satisfying employment, job independence and satisfaction. 


\subsection{Transited youth by category, gender, area of residence, formality and employment sector}

Table 2 shows that young women were more likely to attain stable employment (76.04 per cent) than young men (73.86 per cent). The highest proportion of females was found in stable satisfactory or non - satisfactory jobs (76.04 per cent).

\begin{tabular}{lccc}
\hline Table 2: Transited youth by category and gender (\%) & & & Total \\
Sub-category & 74.50 & 73.86 & 76.04 \\
\hline Stable job, satisfactory or non - satisfactory & 13.84 & 12.33 & 17.46 \\
Satisfactory temporary job & 11.66 & 13.81 & 6.51 \\
Satisfactory self-employment & $\mathbf{1 0 0}$ & $\mathbf{1 0 0}$ & $\mathbf{1 0 0}$ \\
\hline Total & &
\end{tabular}

Source: TLMPS 2014 and authors' calculation

As can be shown in table 3, a significantly higher share of transited men in rural than urban areas ended up in stable employment (38.59 per cent against 34.91 per cent, respectively).

In urban area, young women were more likely to attain stable employment (41.12 per cent) than young men (35.27 per cent).

Rural women are more likely to have satisfactory but temporary jobs (11.24 per cent compared to 5.80 per cent) than rural men. Rural men are more likely to have satisfactory selfemployment (8.51 per cent versus 4.44 per cent) than rural women.

\begin{tabular}{lccc}
\hline Table 3: Transited youth by category, gender and area of residence (\%) & & Gender / \\
\hline Sub-category & $\begin{array}{c}\text { Area of } \\
\text { residence }\end{array}$ & Male & Female \\
\hline Employed in a stable job, satisfactory or non-satisfactory & Urban & 35.27 & 41.12 \\
A satisfactory temporary job & & 5.54 & 6.21 \\
A satisfactory self-employment & Rural & 38.59 & 3.07 \\
Employed in a stable job, satisfactory or non-satisfactory & & 5.80 & 11.24 \\
A satisfactory temporary job & & 8.51 & 4.44 \\
A satisfactory self-employment & $\mathbf{1 0 0}$ & $\mathbf{1 0 0}$ \\
\hline Total
\end{tabular}

Source: TLMPS 2014 and authors' calculation

Figure 5 provides further insights into the drivers of the labor market transition to stable employment, examining the impact of education. The share of stable employment increased with the level of education.

Almost nine-tenths (87.14 per cent of women and 85.71 per cent of men) of university graduates were in stable employment, as were 75 per cent of those who had completed postsecondary and preparatory ( Medium level of education). The lowest share of transited youth in stable employment was received by the group who had low level of education (69.68 per cent of men and 73.33 of women).

The men with low level of education, in contrast, were among those who indicated high satisfaction with self-employment (16.44 per cent).

The results lead to the hypothesis that higher education provided a better chance of completing the labor market transition to stable and/or satisfactory employment.

As seen in table 4, the highest proportion of males and of females have stable job, satisfactory or non - satisfactory jobs in the formal sector (38.09 per cent and 50.31 per cent, respectively).

In contrast, in the informal sector, the proportion of males with satisfactory self-employment is higher than that of females (34.78 per cent versus 25.79 per cent). 
Figure 5: Transited youth by sub-category, sex and levels of education

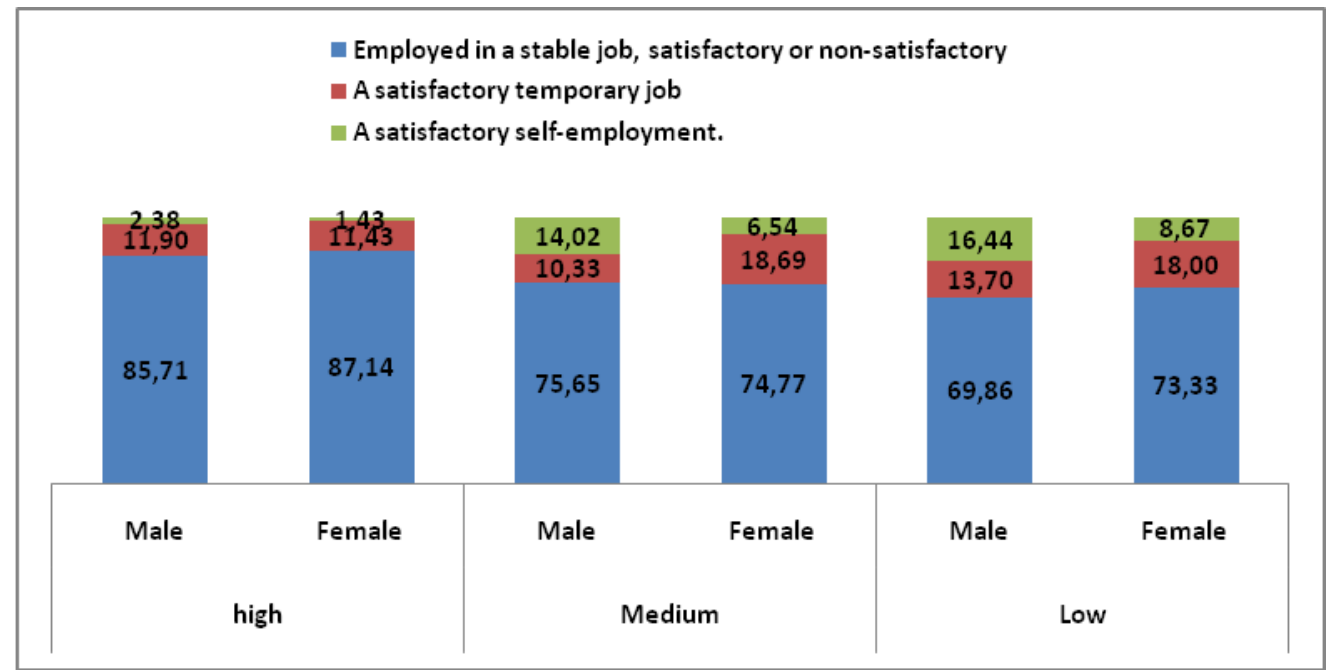

Source: TLMPS 2014 and authors' calculation

\begin{tabular}{lccc}
\hline Table 4: Transited youth by category, gender and formality (\%) & & & Gender / \\
\hline Sub-category & $\begin{array}{c}\text { Area of } \\
\text { residence }\end{array}$ & Male & Female \\
\hline Employed in a stable job, satisfactory or non-satisfactory & Formal & 38.09 & 50.31 \\
A satisfactory temporary job & 4.33 & 8.49 \\
A satisfactory self-employment & 3.57 & 0.94 \\
Employed in a stable job, satisfactory or non-satisfactory & Informal & 34.78 & 25.79 \\
A satisfactory temporary job & & 10.96 & 8.49 \\
A satisfactory self-employment & & $\mathbf{1 0 0}$ & $\mathbf{1 0 0}$ \\
\hline Total
\end{tabular}

Source: TLMPS 2014 and authors' calculation.

Table 4 presents transited youth by category and sector of employment, for men and women respectively.

Men employed in the private sector are more satisfied than those employed in government and in the public enterprise (55.77 per cent, 20.92 per cent and 7.19 per cent, respectively). Similarly, employed women in private sector are more satisfied than those in the government (53.36 per cent and 18.83 per cent, respectively).

Despite the prevailing belief that employees in the public sector have secure jobs since they cannot be dismissed, we found a higher job satisfaction for employees in the private sector.

\begin{tabular}{lccc}
\multicolumn{2}{l}{ Table 5: Transited youth by category, gender and employment sector (\%) } & \\
\hline Sub-category & Employment sector & Male & Female \\
\hline Employed in a stable job, satisfactory or non-satisfactory & Government & 20.92 & 18.83 \\
A satisfactory temporary job & & 1.31 & 2.69 \\
Employed in a stable job, satisfactory or non-satisfactory & Public enterprise & 7.19 & 7.62 \\
A satisfactory temporary job & 1.31 & 2.69 \\
Employed in a stable job, satisfactory or non-satisfactory & Private enterprise & 55.77 & 53.36 \\
A satisfactory temporary job & & 13.51 & 14.80 \\
\hline Total & & 100 & 100 \\
\hline
\end{tabular}

Source: TLMPS 2014 and authors' calculation

In sum, it is interesting to see that:

- Employees in private companies are more satisfied with their jobs than their counterparts in the public sector.

- $\quad$ The percentage of men who have stable jobs is very high. 


\subsection{Job search methods of young employed}

In this subsection, we analyze the job search activities among the employed. The preferred job-search method of both men and women is to contact with employers. Figure 6 shows that about one- third of the employed youth obtained their job in this way.

The second most important channel through which employment was obtained was through send job application/cv (14 percent of men and 21 per cent of women). 13 per cent for men and 12 per cent for women found jobs through family and friends.

While contact with employers dominated as the method of finding jobs for men and women, the third important channel was family and friends, 13 per cent for men and 12 per cent for women found jobs through the help friends.

A lower proportion of employed men found jobs through registered in government employment, 3 per cent versus 11 per cent for women.

Figure 6: Job search methods of young employed by gender (\%)

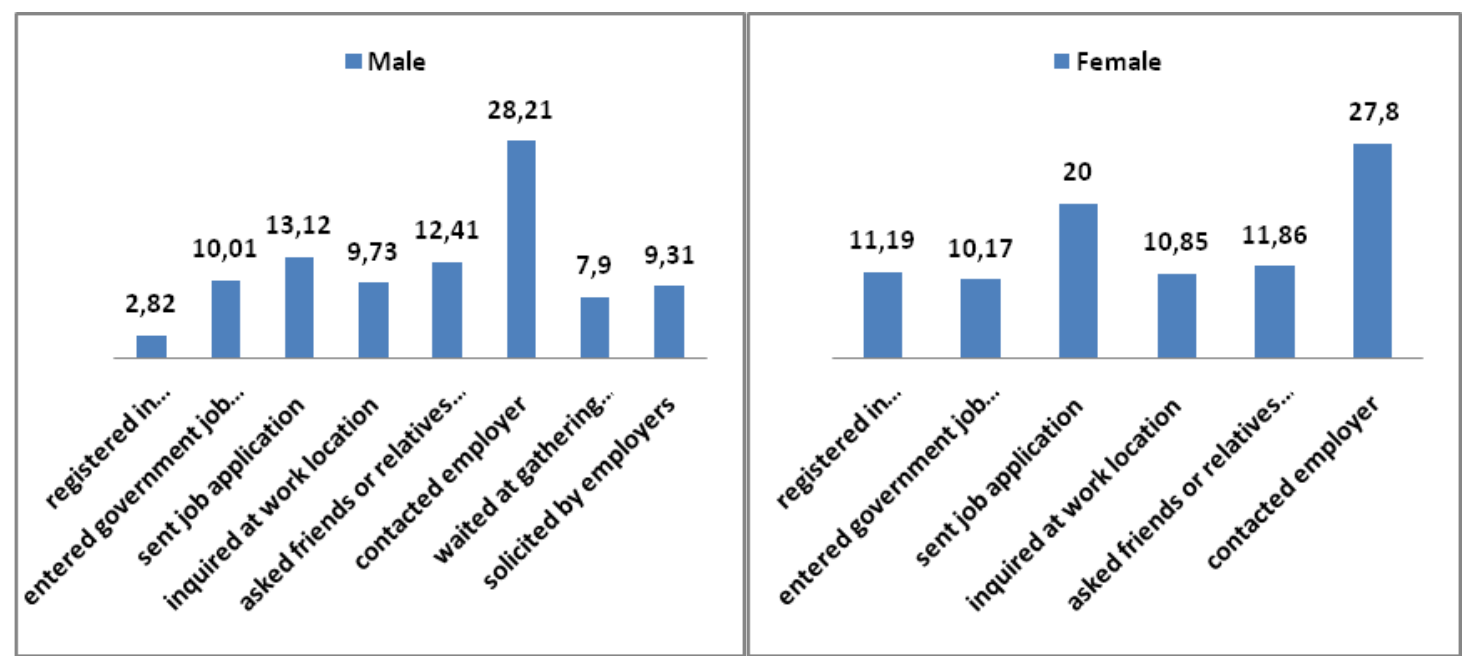

Question: How obtained main job

Source: TLMPS 2014 and authors' calculation

In summary, it can be observed that no substantial differences emerge in the pattern of job search between men and women. Most of the nonworking people have found a job by direct application or contact with the employers and by the help of friends. We conclude that formal inquires with employers are the most widespread search method. Turning to the job placement agencies, job-search via internet or putting advertisements in the mass media have not been that effective strategies

The results confirm that a public employment service is not a decisive factor in securing the scarce jobs in the Tunisian labor market.

\subsection{Average duration of transition}

Transition studies have shown that youth experience increasing difficulties in finding a job at all and a good job in a reasonable time. In this subsection, in order to provide a comprehensive picture of the transition process, it is possible to calculate a lengths of transition from the date of graduation to the first job, to the first "transited" job, to the first "current transited job and to the first "current transited job/ satisfactory job.

The labor market transition of youth concerns not only the length of time between their exit from education to their first entry into any job, but also qualitative elements, such as whether this job is stable. For this reason, we study two cases. In the first, we analyze the transition period to a first job. The speed of transition to the labor market becomes crucial because if people spend too much time looking for a job, they tend to lose confidence and drop out of the labor force to become inactive. The period to first job after leaving school can give an indication of the degree of success youths have had easing into the work force.

In the second case, we look beyond the first job to achievement of a decent or stable job, defined in terms of stability and desire to stay put. 


\subsubsection{Lengths of transition from the date of graduation to the first job}

The transition from the date of graduation to the firs job takes place from the year at which young people are no longer predominately studying without working, to the date at which the majority working without studying. As well, data from TLMPS 2014 give an indication of the average time it takes to find work after graduation or after leaving school. To fully understand the school to work transition, one must look not only at the transition process but also at the activities of youths once they leave school.

Figure 7 provides some indication of the differences in labor market outcomes between those who got a job quickly after leaving school and those who took much longer to get a job. Around 17 per cent of youth got a job within less than 1 year, compared to 59 per cent for those who took over two years to get a job. Two thirds of youth had found the first job after two years.

Men make a faster transition for the first job, 18.6 per cent of male had found the first work within a year, compared with 12.5 per cent of women. This may reflect the stronger tendency for women to work part time for family related reasons and not necessarily a more difficult labor market for women.

It is clear that the transition process has become longer and finding the first job after school can take a long time. Young experience major difficulties in finding a job in a reasonable time.

\section{Figure 7: Percentage distribution of young people by time to first job and gender}

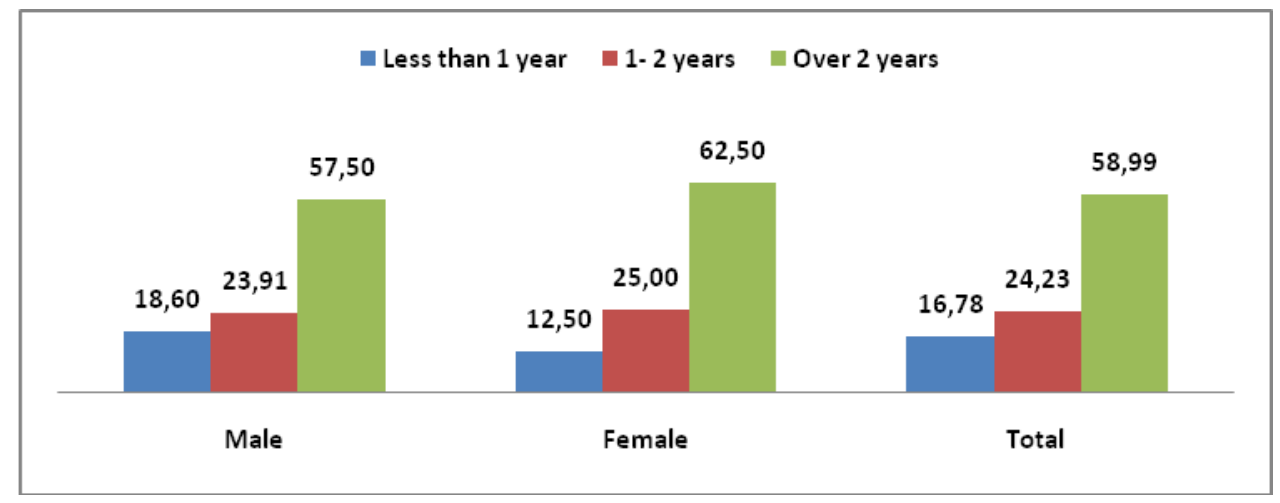

Source: TLMPS 2014 and authors' calculation

Regarding the impact of the level of education, figure 8 clearly shows that youth with high level of education were more likely to attain quickly the first job.

Women who completed quickly the transition to first job (less one year), have high level of education (67.86 per cent), followed by low and medium levels of education with 17.86 percent and 14.28 percent respectively.

For men, 45.92 per cent, 33.67 per cent and 20.41 per cent with low, medium and high levels of education respectively, have completed quickly the first job. Men with low and medium levels of education were much more likely to accept any job, in non-satisfactory self- or temporary employment than women.

The result shows that investing in higher education brings a distinct advantage in terms of finding job quickly without completed the transition to stable employment. The youth with lower levels of education had a higher chance of completing their labor market transition, but not to stable employment

Regardless of the measure, it is clear that the labor market does have a significant problem in absorbing both men and women with low level of education. The main problem remains that too many young people are still looking for work rather than being empowered to invest in their education and then hold out for a job of decent quality. 
Figure 8: Percentage distribution of young people who transited from school to the first job by level of education

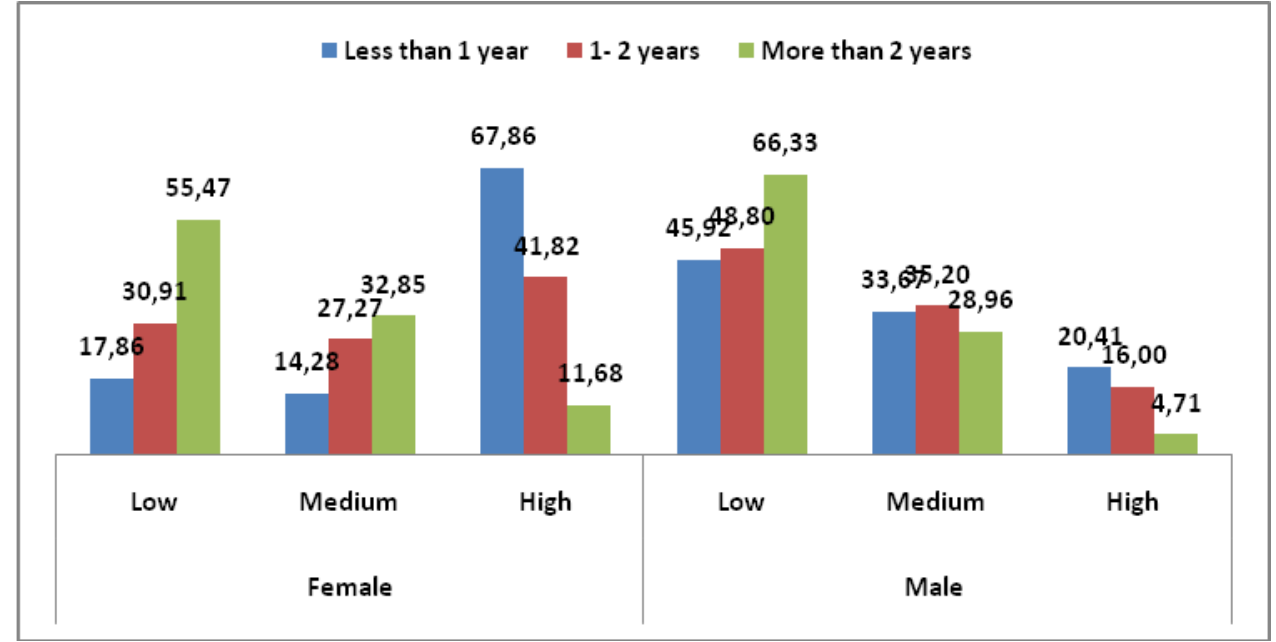

Source: TLMPS 2014 and authors' calculation

Regarding the length of time between leaving school and starting the first job, table 6 shows that the transition to work appears to depend on gender, residence and level of education as well as the interaction between gender and residence and educational level. Five patterns emerge from the table.

- The transition for male youth is particularly short. Females tend to transit to work more slowly than males. The average length of transition for females ( 45.6 months) being longer than their male counterparts (40.32 months). This pattern is consistent also taking into account the breakdown by gender and employment status (i.e. excluding the inactive population and the unemployed).

- Location appears to affect the length of the transition for both males' and females. Urban youth tend to find job more quickly than rural youth.

- Gender appears to be related to the duration of the transition in urban and in rural areas. Urban males and females make the transition to work more quickly than the rural males and females.

- Level of education appears to affect the length of transition. Females with high level education need approximately 24 months to ensure employment against 20 months for males. The lower level of education required longer lengths of transition than medium levels of education.

Table 6: Average lengths of transition to first job: by gender, residence area and by education status (months)

\begin{tabular}{|c|c|c|c|c|}
\hline & & \multicolumn{3}{|c|}{$\begin{array}{l}\text { Lengths of transition to first job(any job, including direct } \\
\text { transitions) }\end{array}$} \\
\hline & & \multicolumn{3}{|c|}{ Mean (months) } \\
\hline & & Total & Male & Female \\
\hline & & 41.64 & 40.32 & 45.6 \\
\hline \multirow{2}{*}{ Area of residence } & Urban & 37.44 & 36.24 & 39.96 \\
\hline & Rural & 45.36 & 43.56 & 40.92 \\
\hline \multirow{3}{*}{ Education Status } & Low & 47.16 & 45.48 & 54.6 \\
\hline & Medium & 42.36 & 37.68 & 55.44 \\
\hline & High & 22.92 & 20.52 & 24.36 \\
\hline
\end{tabular}

Source: TLMPS 2014 and authors' calculation

In the first case, the study's analysis leads the conclusion that the transition from school to the first job is affected more by level of education than by gender and location. We suggested that investing in education is advantageous to the transition paths of young people.

\subsubsection{Transitions beyond first job}

The longer length of transition to the first job can offer meaningful information about the incapacity of the economy to create enough jobs to meet the employment needs of the large cohorts 
of youth entering the labor market. However, limiting the analysis to first job thus misses out on the greater complexity of how young people respond to dynamic labor markets. For this reason, it is necessary to look at the overall transition period, from entry to the labor market through to current decent job.

We start this analysis by studying the situation of youth who finished with the first job compared to those who changed between their first job and current transited job. Figure 9 shows that 49 per cent of youth who have attained their first job stated that they did not decide to change this status. The result indicates that the transition toward the desired job continues beyond the first job.

Figure 9: Percentage distribution of young people in the first transited job

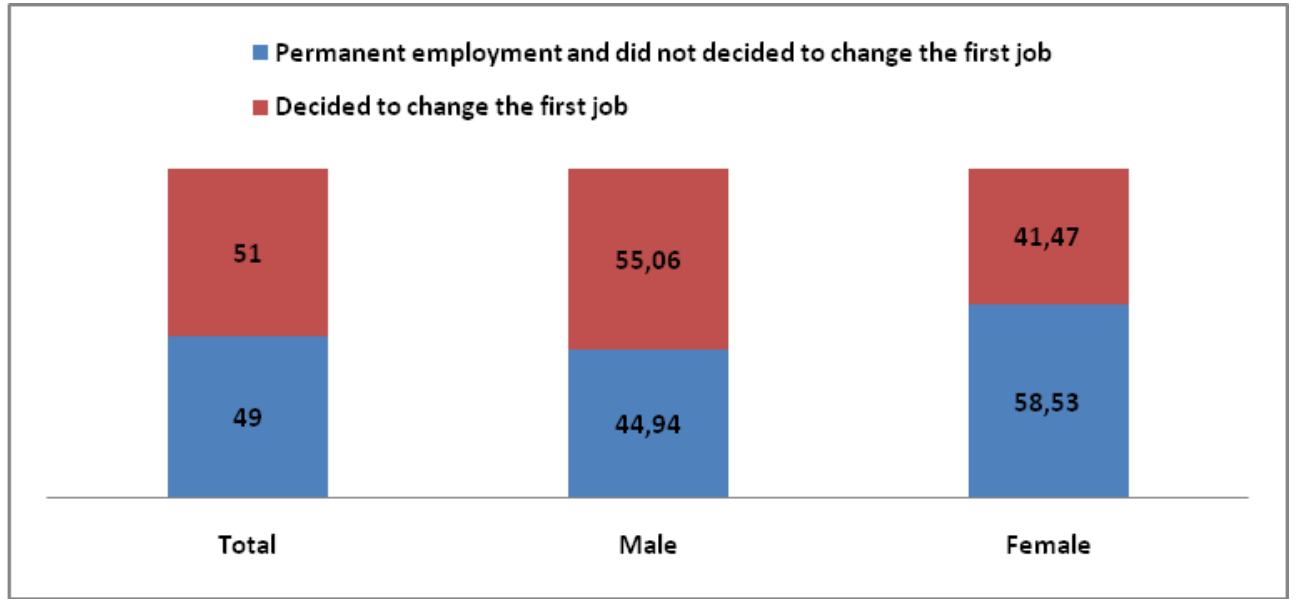

Source: TLMPS 2014 and authors' calculation

Regarding the youth who not decided to change situation, near 71 per cent of them attained quickly the current transition job as their first labor market experience (Figure 9). One third of them tend to transit to work slowly (at over one year).

As shown in figure 9, a large share of transited youth had a short transition to stable and/or satisfactory job. 77 per cent of young people that attained their first stable or satisfactory employment came from mainly direct transition (less than one year).

As can be seen from figures 8 and 9,51 per cent of youth decided to change the first job and one third attained the current job over one year. The result indicates that there is very little turnover in the Tunisian labor market.

Figure 10: Youth who move from the first job to current job by length of transition and gender

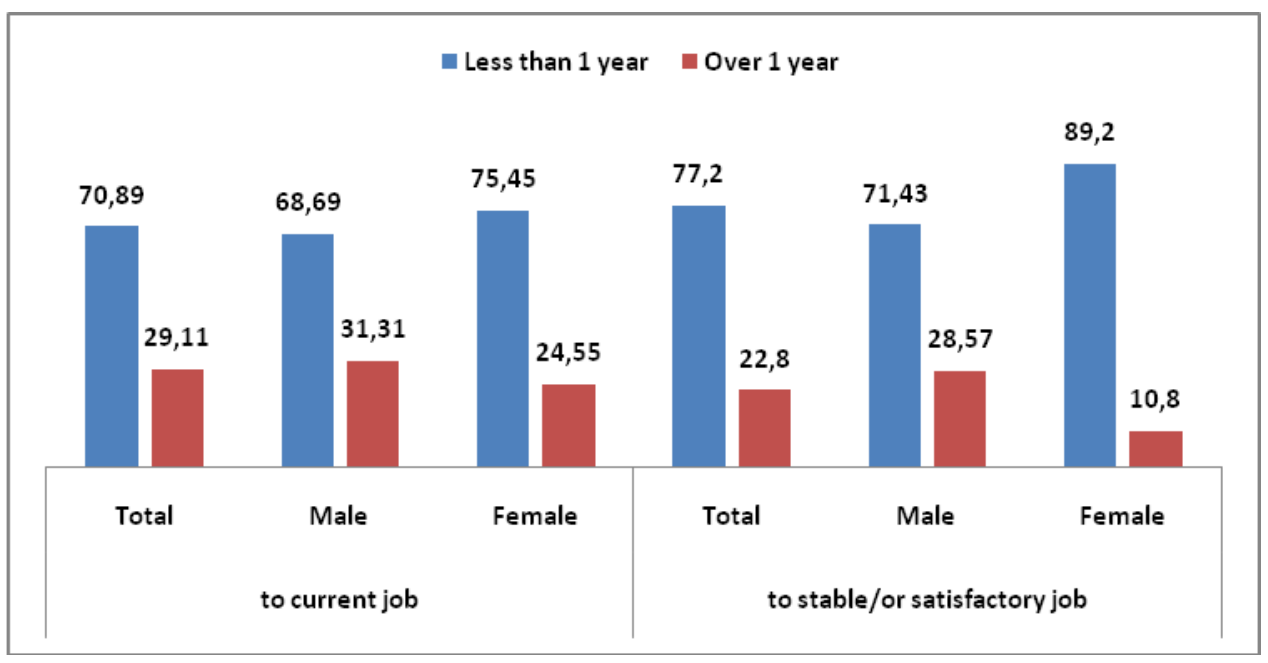

Source: TLMPS 2014 and authors' calculation

Regarding the length of transition, on average, both the young men and women had attained the first transited job 45 months prior. 
Table 7 provides information on the lengths of the school-to-work transition.

- Youth with higher education are not guaranteed an easier transition from school to work. On average, the time between the departure from school to attainment of a fixed term/ or satisfactory job was: 22 months (first transited job) 23 months (current transited stable job) and 25 months (current transited satisfactory job). So the average transition lengths within the sub-categories is not vary widely

- $\quad$ The transition periods were longer for young women than men (47 versus 44 months, respectively) ( first transited job)

- The transition periods were longer for young women than men (48 versus 50 months, respectively) (current transited youth)

- The transition periods were progressively shorter given the increasing education level of the youth (71 months for youth with low level of education versus 22 months for those with a university degree).

- The transition periods were progressively shorter given the increasing level of education: from 22 months for youth with high level of education to 50 months for youth with low level of education.

- On average, the transition for youth in the urban area is less long than that in the rural area.

\begin{tabular}{|c|c|c|c|c|c|c|c|c|}
\hline & & Gende & & Area of & esidence & Educat & & \\
\hline & Total & Male & Female & Urban & Rural & Low & Medium & High \\
\hline $\begin{array}{l}\text { To first transited } \\
\text { job(including direct } \\
\text { transitions }\end{array}$ & 45.12 & 44.76 & 47.04 & 40.8 & 50.4 & 53.64 & 46.68 & 22.92 \\
\hline $\begin{array}{l}\text { To first transited } \\
\text { job(excluding direct } \\
\text { transitions) }\end{array}$ & 52.32 & 51.72 & 55.08 & 48.84 & 56.28 & 50.64 & 59.88 & 33.36 \\
\hline $\begin{array}{l}\text { To current transited } \\
\text { job:/Stability } \\
\text { (including direct } \\
\text { transitions }\end{array}$ & 49.2 & 50.04 & 48.24 & 44.28 & 55.2 & 60 & 49.8 & 23.52 \\
\hline $\begin{array}{l}\text { To current transited } \\
\text { job/Stability(excluding } \\
\text { direct transitions) }\end{array}$ & 56.64 & 57.48 & 56.16 & 56.4 & 61.2 & 66 & 53.88 & 35.04 \\
\hline $\begin{array}{l}\text { To current transited } \\
\text { job/ Satisfactory } \\
\text { job(including direct } \\
\text { transitions }\end{array}$ & 55.68 & 54.72 & 59.52 & 44.88 & 66.72 & 65.16 & 57.36 & 25.44 \\
\hline $\begin{array}{l}\text { To current transited } \\
\text { job/ Satisfactory } \\
\text { job(excluding direct } \\
\text { transitions) }\end{array}$ & 62.4 & 61.92 & 66 & 52.8 & 71.4 & 71.64 & 57.36 & 40.8 \\
\hline
\end{tabular}

Source: TLMPS 2014 and authors' calculation.

These results indicate that transition differs between urban and rural areas, between men and women. Furthermore, they highlight that transition from school to work is more affected by education level. The above evidence indicates that education is more likely to lead to a faster transition to more stable and better matched employment relationships.

In a country like Tunisia, with its high youth unemployment rates, a high frequency of jumping between jobs would not be observed, so the average transition lengths within the subcategories is not vary widely.

\section{Characteristics of youth in transition}

Young people in transition include the unemployed, the inactive and not pursuing education or training with the aim of looking for a job later and the dissatisfied with self-employment and temporary jobs. As shown in Figure 3, youths who were still in transition were largely unemployed (67 per cent) or inactive, non-students with future work aspirations (18 per cent), while 15 per cent of them were in temporary or non-career employment.

In this section, we examine the characteristics of young people in transition putting a strong emphasis on the behavior of the first two groups in this category. For the first category (unemployed), we study the job search methods. For the second category (inactive, non-students 
with future work aspirations), we examine the main reasons behind their lack of motivation to look for work.

\subsection{Distribution of youth in transition not completed according to their characteristics}

We will present some of the characteristics of the inactive youth belonging to unfinished transition category.

Referring to the gender statistics (table 8), the vast majority (65.43 per cent) of youth in transition were unemployed. Another 17.77 per cent of youth in transition, were neither in the labor force nor in education/training (inactive non-students) with a desire to work in the future. The remaining, 16.80 per cent of youth were either "self-employed and unsatisfied" and "employed in a temporary and non-satisfactory job".

The results for in-transition category can be found in Jamaica where the in-transition category includes more males than females (STATIN, SWTS Jamaica 2013).

Both female and male young persons in transition were mostly engaged in non-satisfactory temporary or self-employment (18.3 percent and 14.98 percent respectively) but the females were more inactive (19.57 percent) compared to the males (16.29 percent). The percentage of men and women in the category of unemployment was near 65 per cent.

\begin{tabular}{|c|c|c|c|c|c|}
\hline Sub-category & & Unemployed & Inactive (a) & $\begin{array}{l}\text { Temporary/ } \\
\text { non-career } \\
\text { employment }\end{array}$ & Total \\
\hline \multirow[t]{3}{*}{ Gender } & Male & 65.41 & 16.29 & 18.30 & 100 \\
\hline & Female & 65.44 & 19.57 & 14.98 & 100 \\
\hline & Total & 65.43 & 17.77 & 16.80 & 100 \\
\hline
\end{tabular}

Source: TLMPS 2014 and authors' calculation.

Inactive (a): not in school with the aim of looking for work later. employment

Temporary/non- career employment: Non -Satisfactory job: temporary employment and self-

Looking at the urban-rural distribution (Figure 11), in urban areas the unemployed males are relatively more important among those in transition than the unemployed women (55.61 per cent for males against 44.39 per cent for females).

In rural areas, the share of inactive females is higher than the share of inactive males (56.41 per cent for females against 43.59 per cent for males).

Figure 11: Youth in transition by sub-category and gender and area of residence (\%)

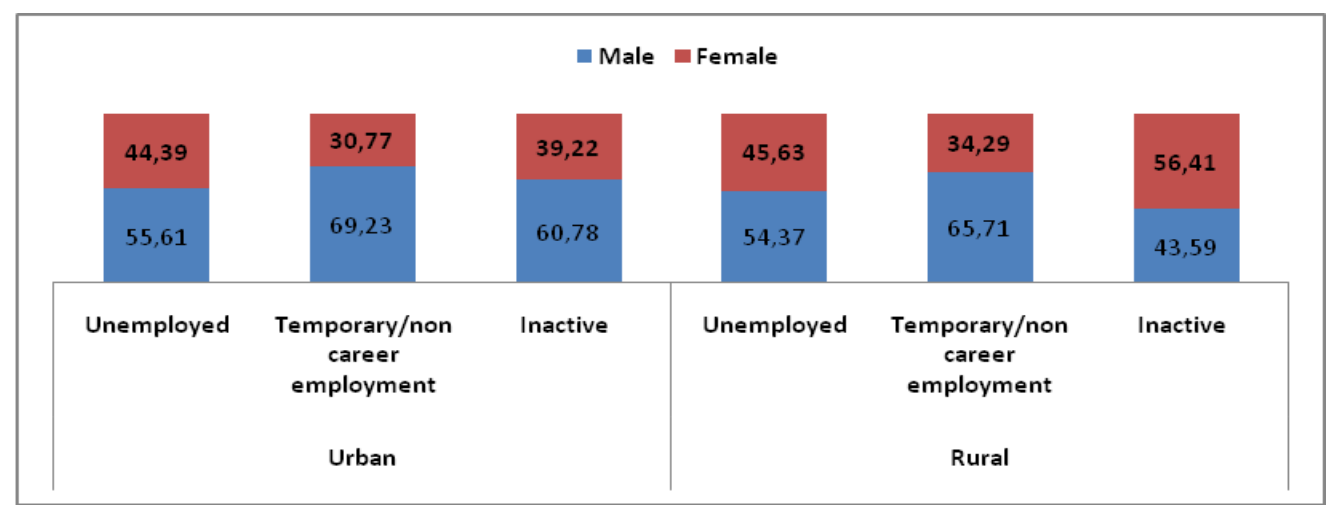

Source: TLMPS 2014 and authors' calculation

As shown in Figure 12, females with higher levels of education were more likely to be in temporary or self-employment (63.16 per cent).

The percentage of unemployment for women with high education levels is higher than that for men with high education levels (72.67 per cent versus 27.33 per cent).

The proportion of men who were inactive with low education levels is lower than that of women with low education levels (38.71 per cent versus 61.29 per cent). 
Having a lower level of education was associated with the probability of being in unemployment for men and having a higher level of education was associated with the probability of being in unemployment for women.

Figure 12: Characteristics of youth in transition by gender and education level (\%)

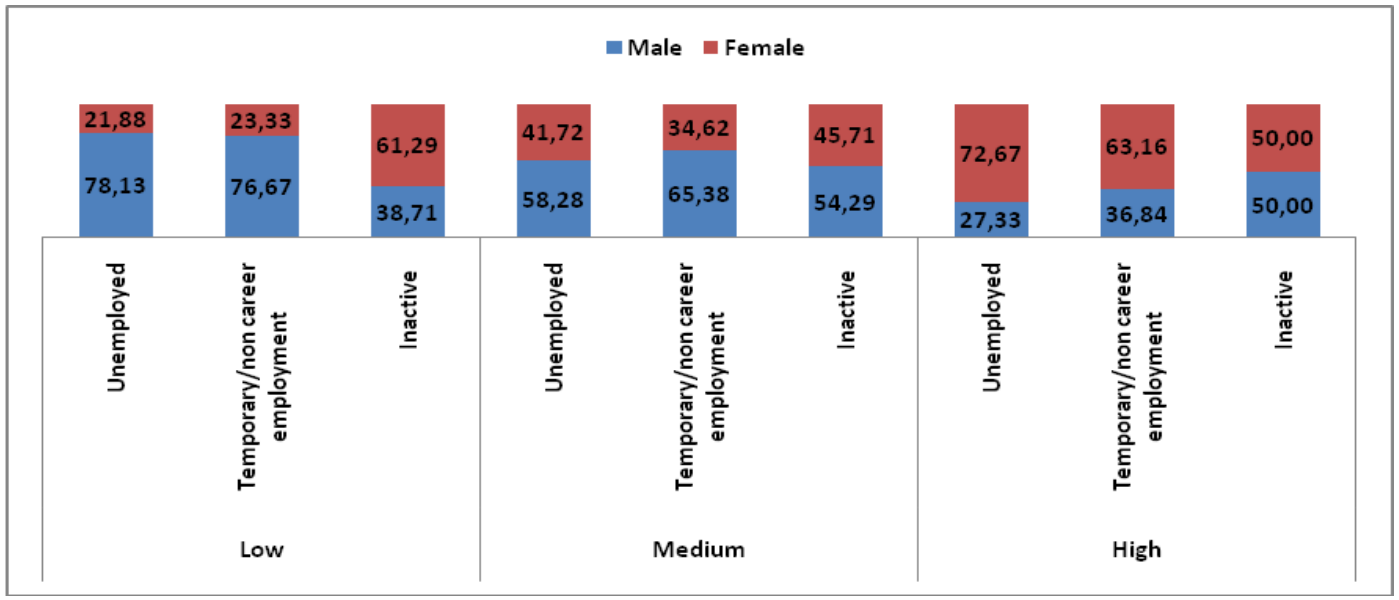

Source: TLMPS 2014 and authors' calculation

\subsection{Reasons of inactivity by young people}

To better understand the foundations of behavior of this inactive and not in education or training category, with the aim of looking for work later, we need to better understand the main reasons behind their lack of motivation to look for work. We believe that young people are considered inactive and not in education or training, with the aim of looking for work later, if they made no specific efforts to find employment and they still want to a job.

As shown in Figure 13, majority of people (40 per cent of men and of women) believe that there are no jobs available. Both of those peoples (men and women), the lack of jobs remains an important factor in exclusion.

No suitable job is the second most important cause of inactivity. A share as high as 26 per cent of men and of women could not find suitable work, while 25 per cent of men and 22 per cent have tired of looking for jobs. Of men, 4 per cent and 3 per cent of women did not know how or where to find work.

Figure 13: Reasons of inactivity by gender (\%)

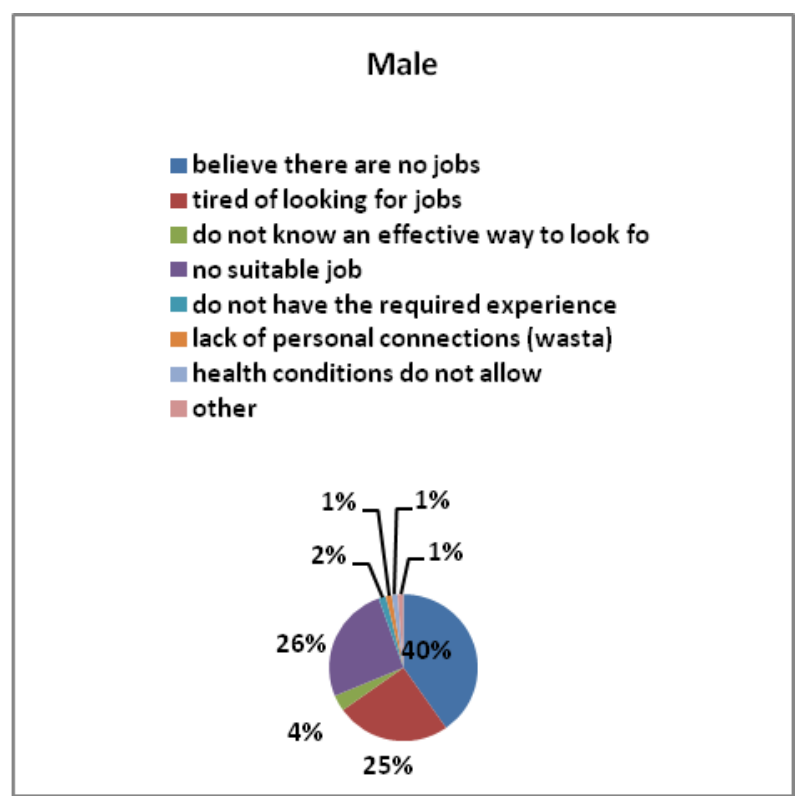

Question: What is the most important reason for not looking for a job?

Source: TLMPS 2014 and authors' calculation 
The young persons interviewed mentioned various reasons for not being able to find work. The three most common reasons were: "believe there are no jobs", "no suitable job" and "tired of looking for jobs".

The previous discussion of youth still in transition conceals differences across women and men, urban and rural areas. Women with lower education levels face higher unemployment rates (unemployed and inactive and not in education or training, with the aim of looking for work later) than males. Men with a higher educational level are a large proportion of the total unemployed. Most of the inactive and not in education or training, with the aim of looking for work later, are women living in rural areas.

Discouraged searchers are people not looking for work because they believe that there are no jobs available. We think that the difficulty in finding suitable work reflects not only a low demand for labor, but also the lack of decent jobs. It is, therefore, of the utmost importance that employers and the Government increase the quality of jobs available, by introducing and implementing arrangements aimed at reducing the long working hours and introduce fiscal incentives to foster the adoption of official work contracts of longer duration.

\subsection{Job search methods of the unemployed}

The preferred job search method of the unemployed by gender is presented in Figure 14. The unemployed youth (men and women) tended to use registration at the public employment services us channel of job search (average 25 per cent), better than searching through family and friends (average 15 per cent) and advertisements in newspapers and other media (average 10 per cent).

Most jobseekers women were searching for jobs through registered in government employment (32 per cent), followed by send job application (16 per cent) and inquire at work location (14 per cent) and family and friends (12 per cent).

Men tended to use three channels of job search: registration at the public employment services (22 per cent), searching for jobs through family and friends (18 per cent) and inquire at work location (17 per cent).

In general, the labor market outcome of initial entry is not an automatic process and is significantly affected by the process of the job search and by the availability of jobs at the time of entry. The method of search and the effort that goes into the youth it are self-determined. This study helps to fill the information gaps by defining the method by which young people continue to seek work if unemployment.

Figure 14: Job search methods of unemployed youth by gender

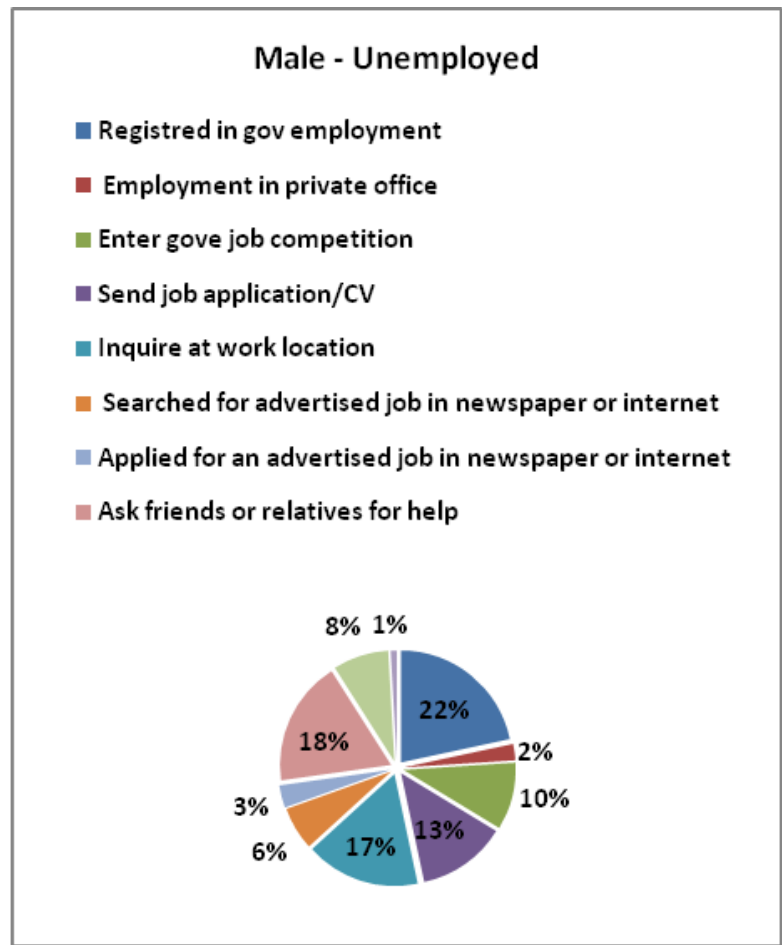

Question: Did you do any other action in past 3 months to find job? Source: TLMPS 2014 and authors' calculation 
In summary, we indicate that young men and women adopted similar search strategies. Turning to the job-search via registered in government employment have not been that the most effective strategies in finding a job.

\section{Estimated average unemployment duration: Kaplan-Meier method}

The aim of this section is to contribute to a better understanding of the factors which affect unemployment duration by investigating the relation between unemployment duration and personal and labor market characteristics, using a Kaplan Meier method. Unemployment duration represents the length of time spent by unemployed people who have been continuously looking for work. Mean duration is the average computed from single weeks (months or years) of unemployment. We provide some interesting details about youth unemployment duration (unemployed and inactive and not in education or training, with the aim of looking for work later).

\subsection{The Data Set}

The sample is restricted to individuals aged between 15 and 35 years, with information concerning personal characteristics. Table 9 gives the frequencies and percentages for different categories of unemployment status. This table shows that of the 2109 individuals in the study, 1579 individuals remained unemployed, and 530 individuals became employed.

The high percentage of young unemployed registered (right - censored data) shows that young people cannot find a job after finishing their studies, as the labor market in the country is not ready to receive them.

\section{Table 9 : Employment status of unemployed individuals}

\begin{tabular}{lcc} 
& Frequency & Percent \\
\hline Right - censored data & 1579 & 74.87 \\
Completed observation & 530 & 25.13 \\
\hline Total & $\mathbf{2 1 0 9}$ & $\mathbf{1 0 0}$ \\
\hline
\end{tabular}

Source: TLMPS 2014 and authors' calculation

Details of the categories of explanatory variables and the descriptive statistics for the duration of unemployment variables are listed in tables 9 and 10.

In data processing we have grouped persons by their educational level in three groups: Low group - Illiterate, Read and Write, Primary, Medium group - Preparatory and secondary school, and High group corresponding to university education (university short cycle, university long cycle and post-graduate).

\begin{tabular}{|c|c|c|c|c|c|}
\hline \multirow[t]{2}{*}{$\begin{array}{l}\text { Explanatory } \\
\text { variable }\end{array}$} & \multirow{2}{*}{$\begin{array}{c}\text { Categories } \\
\\
\text { Total } \\
\end{array}$} & \multirow{2}{*}{$\begin{array}{c}\text { Percentage } \\
100\end{array}$} & \multirow{2}{*}{ 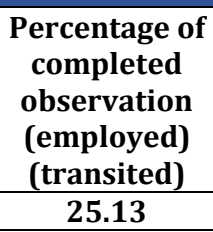 } & \multicolumn{2}{|c|}{$\begin{array}{l}\text { Percentage Right }- \\
\text { censored data } \\
\text { (unemployed) } \\
\text { (in transition) }\end{array}$} \\
\hline & & & & 74.87 & 100 \\
\hline Gender & $\begin{array}{c}\text { Male } \\
\text { Female }\end{array}$ & $\begin{array}{l}41.77 \\
58.23\end{array}$ & $\begin{array}{l}43.25 \\
12.13\end{array}$ & $\begin{array}{l}56.75 \\
87.87\end{array}$ & $\begin{array}{l}100 \\
100\end{array}$ \\
\hline Education status & $\begin{array}{l}\text { High } \\
\text { Medium } \\
\text { Low } \\
\end{array}$ & $\begin{array}{l}17.69 \\
29.92 \\
52.39 \\
\end{array}$ & $\begin{array}{l}32.44 \\
27.58 \\
21.27 \\
\end{array}$ & $\begin{array}{l}67.56 \\
72.42 \\
78.73\end{array}$ & $\begin{array}{l}100 \\
100 \\
100\end{array}$ \\
\hline Area of residence & $\begin{array}{c}\text { Urban } \\
\text { Rural }\end{array}$ & $\begin{array}{l}41.01 \\
58.99 \\
\end{array}$ & $\begin{array}{l}29.25 \\
22.27 \\
\end{array}$ & $\begin{array}{l}70.75 \\
77.73 \\
\end{array}$ & $\begin{array}{c}100 \\
100 \\
\end{array}$ \\
\hline
\end{tabular}

Source: TLMPS 2014 and authors' calculation

\subsection{Results of the Kaplan-Meier}

The Kaplan-Meier technique is a nonparametric method for estimating time-related events by creating a new variable that represents people reaching the employment event, and those failing to reach that event (employment). Its curve can take into account "censored" data losses from the sample before the final outcome is observed (see table A2 in appendix). 
We use this method to analyze both the length of time people remain unemployed after leaving school or after job loss and the influence of gender, age, area of residence, and educational level on unemployment duration. We notice that unemployment duration is an important variable which can explain changes in labor markets when examining flows between employment, unemployment and out of the labor force.

A plot of the Kaplan-Meier estimate of the survival function is a series of horizontal steps of declining magnitude which, when a large enough sample is taken, approaches the true survival function for that population. Small vertical tick-marks indicate losses, where patient data has been censored.

The Kaplan Meier estimator of the survival function for all youth (employment and unemployment) is presented in figure 15 which illustrates the survival curve for unemployment duration. Points on this curve estimate the proportion of individuals who remained unemployed over time

The curve shows that the probability of survival is 0.8 in the first year of our study period. We say that the probability of finding a job and leaving the unemployment situation is very high for new comers.

Figure 15: Survival function estimates for all unemployed

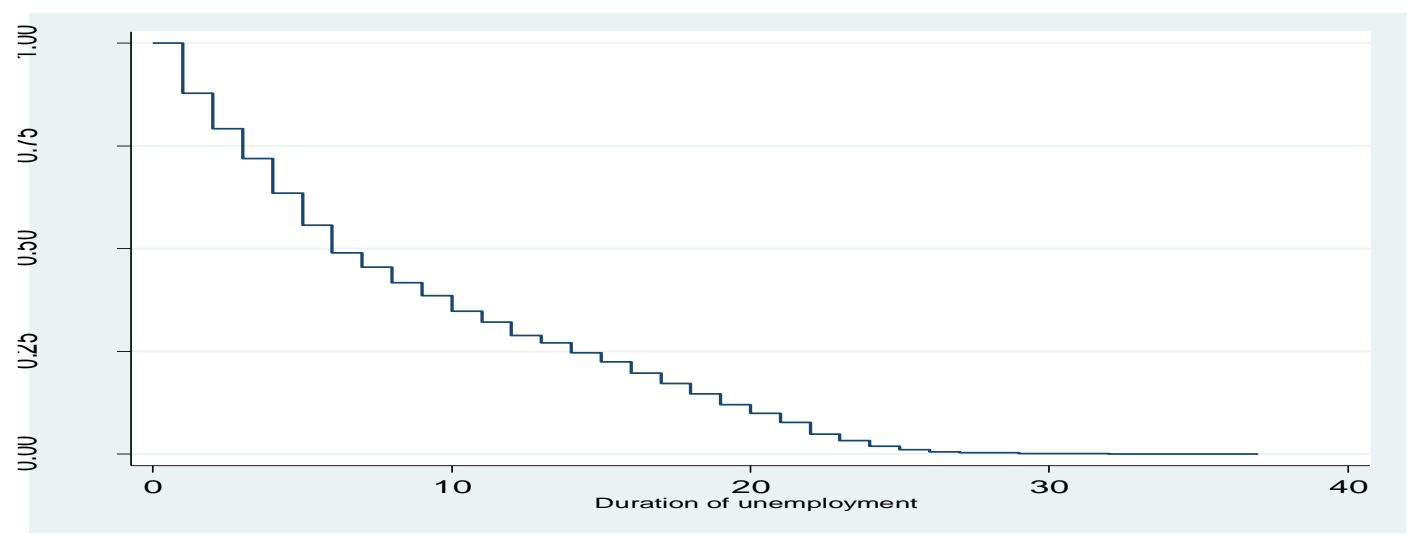

Source: TLMPS 2014 and authors' calculation

Figure 16 depicts only the two extreme levels of the factor gender with the highest and lowest probability of survival, namely the survival curves for men and women, respectively, to make the figure easier to read. The survival function indicates that there are significant differences with an advantage for men over women.

The estimate of the unemployed from women decreases to 0 at a much slower rate, indicating that the unemployed men have a far better position in the labor market. We notice that after 25 years the curves coincide.

Figure 16: Survival function by gender

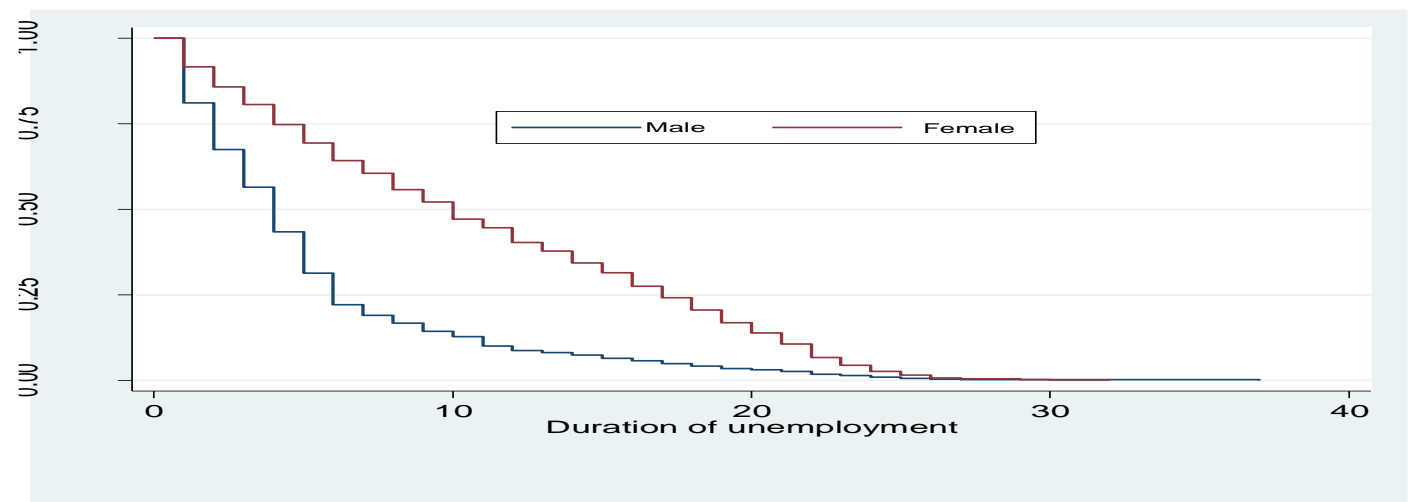

Source: TLMPS 2014 and authors' calculation

Another concern of this study is to investigate unemployment duration by area of residence. Figure 17 shows the corresponding curve for rural areas is higher than that of urban areas, 
meaning that for the same period, the probability of remaining unemployed is higher for rural than for urban areas.

However, beyond 10 years and 15 years of unemployment, the probability of remaining unemployed is the same for both urban and rural areas.

Unemployed women from rural areas have a higher probability of remaining unemployed. We believe that it may be more difficult for them to adapt to the new labor market conditions.

Figure 17: Survival function by gender and area of residence

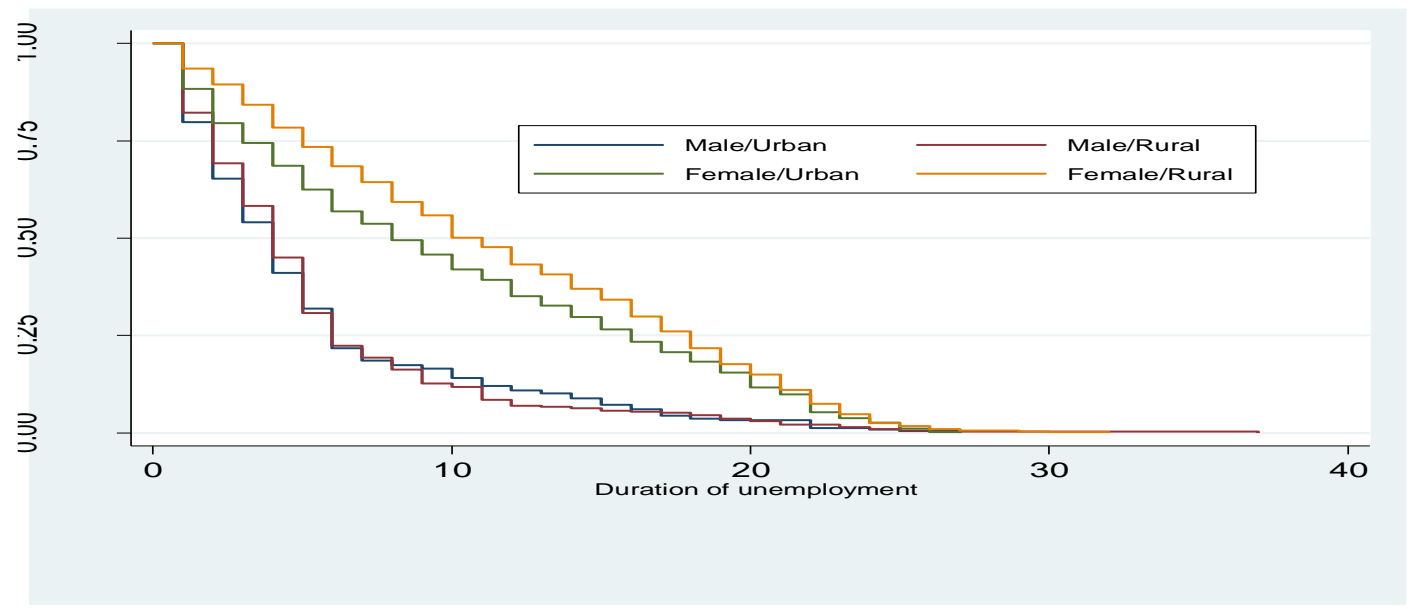

Source: TLMPS 2014 and authors' calculation

Concerning educational level, we have considered three educational levels: level one refers to lower education, level two refers to medium and three refers to higher education.

In figure 18 there is presented the survival curve for the three groups concerning the educational level described in this research. We can notice in the figure that for the group 3 high education level, the probability of unemployment at time t or later decreases much more rapidly. Unemployed with higher education has better opportunities in the labor market.

Group 1, with low education level, followed by group 2, with medium education level, registers the lowest employment probability. We can notice in the figure that after 25 unemployment years curves start to coincide and the educational level no longer influences the probability of finding a job.

Higher education has a positive effect on probability of leaving unemployment. One of the reasons for this pattern is the fact that more educated individuals are more selective in accepting job offers and may look for a job for a longer period.

Figure 18: Survival function by gender and education level

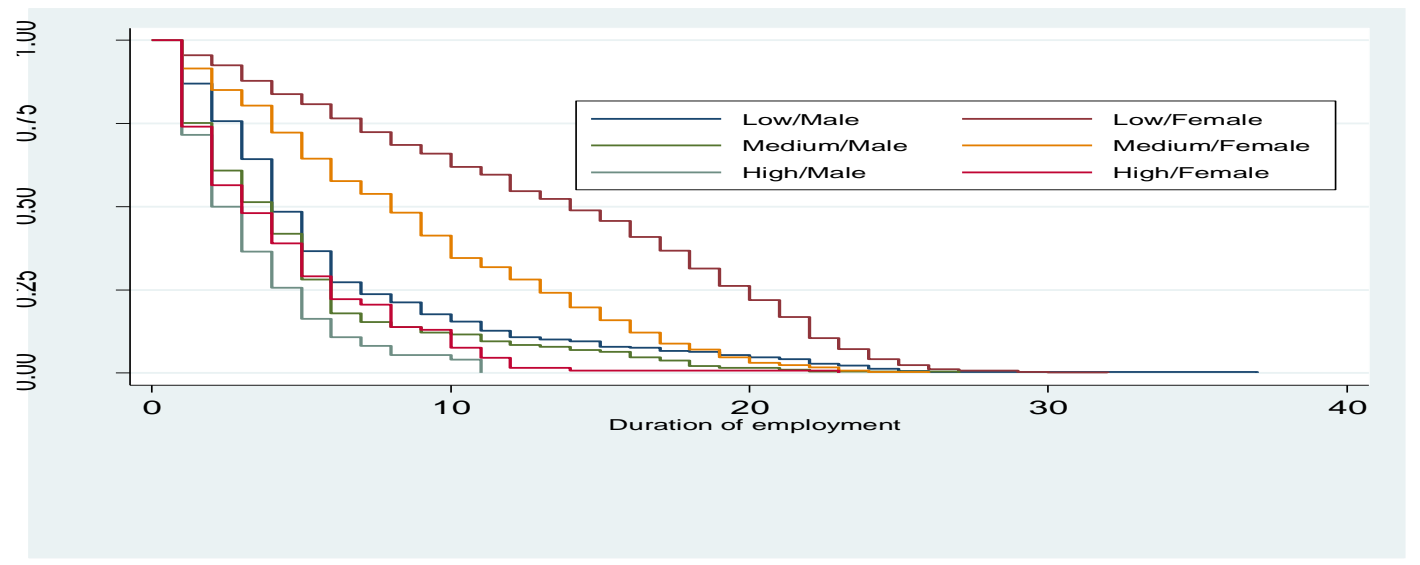

Source: TLMPS 2014 and authors' calculation

In order to confirm the results obtained graphically from the Kaplan-Meier estimates of the survival functions, we used the log rank test with Chi-Squared distribution under the null hypothesis which that curves should be the same for the two levels of a factor. 
For gender, area of residence, and education level variables, the highly significant p-values $(p$-value $=0.000)$ confirm the results that curves are different (Table A3 in Appendix).

In our analysis, we distinguish between the unemployed and the employed. Bearing on the results of the survival analysis, we may conclude that:

- Unemployment duration is lower for high-educated young.

- There are large differences in unemployment duration between women and men. Women are more likely to become long term unemployed.

- Average unemployment duration is high for women, especially for women with low education levels.

- Average unemployment duration is high in rural areas, for women, especially for women with low education levels.

\section{Conclusions and recommendations}

This paper examined the factors which explain the transition from school to work and some of the issues related to the youth unemployment problem by using the individual data extracted from the "TLMPS in 2014" survey. The main findings are as follows.

First, the labor market situation of young surveyed was markedly different, usually very much to the advantage of men. Looking at the data under a different angle, the largest share of young women had not started their transition while the largest share of young men had completed their transition. Young women were more likely to attain stable employment than young men.

Males were more as likely as females to have completed the transition, with the greatest percentage of transited young women having attained a stable job.

Regarding the distribution of transited youth in stable employment, most youth gained employment in private sector. Furthermore, the share of stable employment increased with the level of education.

Most young workers surveyed expressed a high degree of job satisfaction, although as many as one-half of working (first job) youth indicated they would like to change their first job.

A large majority of employed youth found their current jobs through contact with employers, while the unemployed youth tended to use other channels of job search through registration at the public employment services and family and friends. Lack of job opportunities is often invoked by youths as a reason for not looking for a job.

Second, using the historical path, it is possible to identify the labor market categories held by the young person prior to transiting to stable or satisfactory employment. The majority of transited youth attained their first job over than two years while the majority of youth transit from the first job to the current job quickly as their first labor market experience. Furthermore, a large share of transited youth had a short transition to stable/or satisfactory job. The majority was in a stable and satisfactory job. Location and level of education appear to affect the length of the transition for both males and females. The youth with lower levels of education had a higher chance of completing their labor market transition. Urban youth find job more quickly than rural youth.

Finally, the results of basic data analysis of the duration of unemployment spells using Kaplan - Meier curves show that the unemployed with the higher education have better opportunities in the labor market while youth with low level of education registers the lowest employment probability. Unemployment duration is on average the smallest for men, for individuals living in urban areas.

These results may be useful to policy makers, both for the public and private sectors, and to employers in general.

Policies, including effective public - private partnerships for the placement and training of job seekers, need to be a priority. These policies can be designed to:

- increase the opportunities and the ability of young men and women

- Give young people who have not yet transited or are not satisfied with their job a second chance allowing them to find more productive opportunities.

- Help motivate job-seekers, especially the long term unemployed, improve their employability and expand their opportunities to be placed and retained in appropriate jobs.

- Encourage local employment initiatives and implement the appropriate policies for the region to benefit from such initiatives.

- Establish an accessible database of available jobs and disseminate it through social media in order to create an easier interface for youth and employers.

These measures should provide solutions that would promote regional development and reduce territorial disparities. 


\section{Acknowledgment}

\section{Funding}

The authors received no direct funding for this research.

\section{Citation information}

Kriaa, F., \& Bouhari, M. (2018). Characterizing the school-to-work transitions of young men and women in Tunisia. Economics, Management and Sustainability, 3(2), 85-106. doi:10.14254/jems.2018.3-2.7.

\section{References}

Circelli, M., \& Oliver, D. (2012). Youth transitions: What the research tells us. A National Centre for Vocational Education Research Consultancy Report. Adelaide: National Centre for Vocational Education Research.

Boughzala, M. (2004). The Labor market in Tunisia: Study on the functioning of the labor markets in the Mediterranean Region and the implications for employment policy and training systems. University of Tunis..

Elder, S. (2009). ILO school-to-work transition survey: a methodological guide. ILO, Geneva.

El Zanaty \& Associates. (2007). The school-to-work transition: Evidence from Egypt. Employment Policy Papers

Ghada, B., Ramadan, M., \& Mostafa, M. (2014). Labour market transitions of young women and men in Egypt. Work4Youth Publication Series No. 16 International Labour Office Geneva.

Fares, J., Guarcello, L., Manacorda, M., Rosati, F., Lyon, S., \& Valdivia, C. A. (2005). School to work transition in Sub-Saharan Africa: An overview. UCW Working Papers, November 2005.

Haouas, I., Sayre, E., \& Yagoubi, M. (2012). Youth unemployment in Tunisia: Characteristics and policy responses. Topics in Middle Eastern and North African Economies, 14.

Havet, N. (2006). L'insertion professionnelle des jeunes et mesures publiques: des trajectoires différenciées entre hommes et femmes. Annales d'économie et de statistique, 81, 225-251.

Machado, J. A., Portugal, P., \& Guimaraes, J. (2006). US unemployment duration: Has long become longer or short become shorter?. IZA Discussion Paper No. 2174.

Stampini, M., \& Verdier-Chouchane, A. (2011). Labor market dynamics in Tunisia: the issue of youth unemployment. Review of Middle East Economics and Finance, 7(2), 1-35.

Matsumoto, M., \& Elder, S. (2010). Characterizing the school-to-work transitions of young men and women: Evidence from the ILO school-to-work transition surveys (No. 994572743402676). International Labour Organization.

Ries, J. (2012). Regards sur le halo du chômage. STATEC, INSEE, Avril 2012.

Ryan, P. (2003). The School-to-Work transition: Problems and Indicators. In A.N. Perret-Clermont, C. Pontecorvo, L. Resnik, T. Zittoun \& B. Burge (ed.s), Youth Learning and Society, CUP, Cambridge.

Sengenberger, W. (2011). Beyond the measurement of unemployment and underemployment. ILO Working Paper, Geneva: International Labour Organization.

Barcucci, V., \& Mryyan, N. (2014). Labour market transitions of young women and men in Jordan. ILO.

Institut National de la Statistique(2012). Enquête nationale sur la population et l'emploi 2012. (décembre 2013).

Observatoire National de l'Emploi et des Qualifications. (2013). Rapport annuel sur le marché du travail en Tunisie, Décembre 2013.

The Statistical Institute of Jamaica: The Planning Institute of Jamaica. (2014). Labour market transitions of young women and men in Jamaica. Work4Youth Publication Series No. 17.

World Bank. (2004a). République tunisienne - Stratégie d'emploi. Rapport No. 25456- TUN, MoyenOrient et Afrique du Nord Secteurs sociaux (MNSHD), Washington DC.

World Bank. (2008). Youth in Africa's Labor Market. 


\section{Appendix}

The authors received no direct funding for this research.

\begin{tabular}{|c|c|}
\hline Transited & - a stable job, whether satisfactory or non-satisfactory; or \\
\hline A young person is currently & - a satisfactory but temporary job; or \\
\hline employed in: & - Satisfactory self-employment. \\
\hline In transition & - unemployed (relaxed definition); or \\
\hline A young person is currently: & $\begin{array}{l}\text { - employed in a temporary and non-satisfactory job; or } \\
\text { - in a non-satisfactory self-employment; or } \\
\text { - inactive and not in education or training, with the aim of looking for } \\
\text { work later. }\end{array}$ \\
\hline $\begin{array}{l}\text { Transition not started } \\
\text { A young person is one who is } \\
\text { currently: }\end{array}$ & $\begin{array}{l}\text { - still in school and inactive (inactive student); or } \\
\text { - inactive and not in education or training (inactive non-student), with } \\
\text { no intention of looking for work. }\end{array}$ \\
\hline
\end{tabular}

\section{Table A11: Kaplan - Meier}

\section{Survival analysis of unemployment duration: Method Kaplan-Meier}

Kaplan-Meier Method, called the product-limit estimator, was developed by Kaplan and Meier. This method is used in medical studies where "death" and "alive" are used frequently. In the context of this paper, we replace "death" by employment and "alive" by unemployed.

$S(t)$, the survival function is the probability of an individual surviving (remaining unemployed) at $t$ units of time from the beginning of the study.

In general, the survival function $S(t)=P(T\rangle t)$ ) gives the population probability of surviving beyond $t$, where $T$ is a random variable called lifetime or survival time (1958). The cumulative distribution of $\mathrm{T}$ is $F(t)=P(T \leq t)$ and the probability density function is $f(t)=\frac{d F(t)}{d t}$. This means the survival function $S(t)=1-F(t)$.

The Kaplan-Meier estimator is a simple method allowing the computation of an estimated survival function in the presence of right censoring.

$$
S(k)=S(k-1) p_{k}=p_{1} \times p_{2} \times \ldots \times p_{k}
$$

$p_{k}$ is the proportion of individuals surviving at least the $k$ th year after they have survived $(k-1)$ years.

Denotes $d_{i}$ as the number of observed events at time $t_{i}$ and $n_{i}=d_{i}+r_{i}$ is the number of subjects whose event time is not less than, where $r_{i}$ is the number of subjects alive after time $t(i)$.

The PL estimate of survival probability at time $t$ was proposed by Kaplan Meier as: $S(t)=\prod_{t_{i} \leq t}\left(1-h_{i}\right)=\prod_{t \leq t}\left(1-\frac{d_{i}}{n_{i}}\right)$ if $t>$ the first uncensored event time and $S(t)=1$ before that. 


\begin{tabular}{ccccccccc}
\hline Table 12: Log-rank test for equality of survivor functions \\
\hline Gender & $\begin{array}{c}\text { Events } \\
\text { observed }\end{array}$ & $\begin{array}{c}\text { Events } \\
\text { expected }\end{array}$ & $\begin{array}{c}\text { Level of } \\
\text { education }\end{array}$ & $\begin{array}{c}\text { Events } \\
\text { observed }\end{array}$ & $\begin{array}{c}\text { Events } \\
\text { expected }\end{array}$ & $\begin{array}{c}\text { Area of } \\
\text { residence }\end{array}$ & $\begin{array}{c}\text { Events } \\
\text { observed }\end{array}$ & $\begin{array}{c}\text { Events } \\
\text { expected }\end{array}$ \\
\hline Male & 579 & 343.32 & Low & 918 & 1147.10 & Urban & 624 & 563.88 \\
Female & 1028 & 1263.68 & Medium & 484 & 372.13 & Rural & 983 & 983.00 \\
Total & 1607 & 1607.00 & High & 205 & 87.77 & Total & 1607 & 1607.00 \\
& chi2(1) & 249.07 & Total & 1607 & 1607.00 & & chi2(1) & 11.39 \\
& Pr>chi2 & 0.0000 & & chi2(1) & 285.44 & & Pr>chi2 & 0.0007 \\
& & & Pr>chi2 & 0.0000 & & & \\
\hline
\end{tabular}

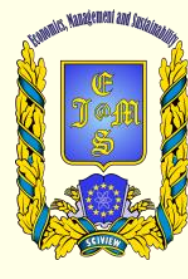

(C) 2016-2018, Economics, Management and Sustainability. All rights reserved.

This open access article is distributed under a Creative Commons Attribution (CC-BY) 4.0 license.

Share - copy and redistribute

The licensor cannot revoke these freedoms as long as you follow the license terms.

Under the following terms:

Attribution - You must give appropriate credit, provide a link to the license, and indicate if changes were made.

You may do so in any reasonable manner, but not in any way that suggests the licensor endorses you or your use.

No additional restrictions

You may not apply legal terms or technological measures that legally restrict others from doing anything the license permits.

Economics, Management and Sustainability (ISSN: 2520-6303) is published by Scientific Publishing House "CSR",

Poland, EU and Scientific Publishing House "SciView", Poland

Publishing with JEMS ensures:

- Immediate, universal access to your article on publication

- High visibility and discoverability via the JEMS website

- Rapid publication

- Guaranteed legacy preservation of your article

- Discounts and waivers for authors in developing regions

Submit your manuscript to a JEMS at http://jems.sciview.net or submit.jems@sciview.net

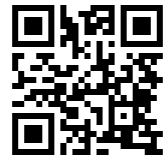

